\title{
Using a World Café to Explore New Spaces and New Models for Front Line Services: A Case Study from the Irish University Library Sector
}

\section{Helen Fallon \& Laura Connaughton}

To cite this article: Helen Fallon \& Laura Connaughton (2016): Using a World Café to Explore New Spaces and New Models for Front Line Services: A Case Study from the Irish University Library Sector, New Review of Academic Librarianship, DOI: 10.1080/13614533.2015.1126291

To link to this article: http://dx.doi.org/10.1080/13614533.2015.1126291

曲 Published online: 25 Jan 2016.

Submit your article to this journal $\pi$

Q View related articles $\sqsubset$

View Crossmark data 


\title{
Using a World Café to Explore New Spaces and New Models for Front Line Services: A Case Study from the Irish University Library Sector
}

\author{
Helen Fallon and Laura Connaughton \\ Maynooth University, Maynooth, County Kildare, Ireland
}

\begin{abstract}
World Café, sometimes termed Knowledge Café, is now an established method of facilitating productive dialogue between a group or groups of people around an issue that matters to the group as a whole. Now a world movement, the methodology is straightforward and uses conversation as a key process to connect people, who may be from different organizations, age groups, cultures, continents, and so forth. Café conversations draw on the wisdom and creativity of the participants to explore issues of concern to them and to confront real life challenges. Following some background information and a brief review of the literature relating to the World Café, this article presents a case study of the application of the model to facilitate discussion and learning around a topic of common concern, frontline desk services, for 61 staff from 11 Irish academic libraries at Maynooth University (MU) Library in October 2015. This was part of a one-day staff development event: MU Library Innovation Day. The application of the World Café methodology is described. The results of the evaluation of the event are presented and discussed. Actions and outcomes are provided. Limitations of the case study are presented.
\end{abstract}

\section{KEYWORDS}

World Café; staff

development; university libraries; ireland; frontline services

\section{Introduction}

The Maynooth University (MU) Library Word Café took part in a climate of cooperation that is very much a feature of the Irish Higher Education system. There are seven universities in the Republic of Ireland (RoI), 14 Institutes of Technology (IoTs) focusing on applied research and a number of other colleges that are under the responsibility of the Higher Education Authority (HEA). Following a period of expansion of the sector from the mid-nineties, the sharp downturn in the Irish economy in 2008 has resulted in the decrease of funding to the sector from approximately $€ 2$ billion in 2009 to $€ 1.5$ billion in 2014, a reduction of $25 \%$ (Ireland, Oireachtas Library and Research Service, 2014).

CONTACT Helen Fallon Helen.B.Fallon@nuim.ie 0 Library, Maynooth University, Maynooth, County Kildare, Ireland. 
Irish university libraries have a strong tradition of cooperation. The Consortium of National and University Libraries (CONUL) is a consortium of Ireland's main research libraries. Its mission is to develop and improve services in member libraries. CONUL has fostered a spirit of collaboration to develop services and realize greater value for money. It has established six sub-committees with membership from across its 13 member libraries to advance its mission. These are: regulatory affairs; collections, conservation and preservation; teaching and learning; digital services and infrastructure; research support and the staff training and development sub-committee, also known as Academic and National Library Training Cooperative (ANLTC). The ANLTC sub-committee has representation from all CONUL-member libraries. Each participating library organizes a course each year. Generally, this is a one-day program. Working as a cooperative, ANLTC has been in a position to offer courses that an individual library might not have sufficient numbers or funding to run.

In 2015, Maynooth University Library hosted MU Library Innovation Day as part of the ANLTC program. The theme of MU Library Innovation Day was New Spaces and New Models for Frontline Services. There were three main elements to the program: a tour of the new MU Library, short presentations on frontline services in CONUL-member libraries, and a Word Café. The World Café is the focus of this article. This is the first World Café event for staff from CONUL-member libraries. We (the two authors) opted to run a World Café as we had some familiarity with the model. We had used this method in our MU Library Organisational Review (Fallon \& Bean, 2014) and in the MU Library 2015 Library Strategic Planning process. We recognized that the ANLTC library group, with their diverse backgrounds, would have a vast range of skills, knowledge, and experience and we wanted to tap into that collective experience and knowledge.

...the World Café has been categorized as one of a new generation of participatory methods that attempt to achieve collective change by bringing all members or stakeholders of the system together in one place, using a highly structured process of movement to creative flexible and coevolving networks of conversation (Jorgenson \& Steier, 2013, p. 393).

The World Café was developed by Juanita Brown and David Isaacs in 1995, when 24 business and academic leaders got together for a meeting at their California home (Brown \& Isaacs, 2005; Brown, Isaacs, \& Tan, 2008; Brown, Isaacs, Margulies, \& Warhaftig, 1999). While waiting for the rain to stop, they gathered in small groups around tables and began to explore the issues that had brought them together, recording their insights with markers on paper tablecloths. People moved between tables; ideas and insights circulated and were explored in different groups. They found this enriched the conversation, generating creative ideas and learning together in a more engaging and participative way than in traditional meetings. Harvesting the notes from the paper tablecloths, they noticed emerging patterns in their conversations and this generated more ideas. 
The method has seven core design principles:

- It must have a clear purpose

- It must be hosted in a hospitable space

- It must explore questions that matter to participants

- Everybody's contribution is encouraged and valued

- It connects diverse viewpoints

- People listen together for insights and discoveries

- Participants share collective discoveries (adapted from Brown \& Isaacs, 2005, p. 40)

Following a review of the literature, the article goes on to describe and evaluate the MU Library World Café.

\section{Literature review}

The World Café website (www.theworldcafe.com) offers a range of documentation on the World Café method, including links to a number of articles from professional journals. While the World Café formally developed as a methodology for creative dialogue in 1995 (Brown \& Isaacs, 2005; Schieffer, Isaacs, \& Gyllenpalm, 2004), the concept of using dialogue to facilitate the growth of people and organizations, which underpins the World Café concept is not new. Senge (1990) suggests that dialogue fosters organizational learning noting that dialogue was revered as a method of learning by the ancient Greeks and practiced by the American Indians, but is much less valued in today's world. He suggests that dialogue between groups creates a trust leading to a deeper understanding of different points of view. This dialogue creates a "larger pool of meaning" accessible to the group. Because it is grounded in reflection and inquiry skills, this "larger pool of meaning" is likely to be more reliable and less dependent on particulars of circumstance, such as the chemistry among team members (Senge, 1990, p. 249).

World Café has been used by diverse groups and organizations and adapted to the circumstances of participants. Hovath (2005) describes how the World Café was used by over seven hundred people in Saudi Aramco, Saudi Arabia's national oil company. The café was hosted in an aviation hangar, which was transformed by Arabian carpets into a hospitable space; the carpets also served to muffle sound. As a method it helped bridge organizational hierarchies and built on Arab society's historical tradition of hospitality and conversation.

I've discovered that the Café concept strikes a familiar cord, not only with Saudi Arabs but with the many other cultures that are represented in the company. Whether people are Egyptian, Turkish, Malaysian, American, or Korean, they all have cultural traditions of sitting down together in a social setting to discuss their hopes and dreams for the future (Hovath, 2005, p. 72).

A comparative study of World Café and Large Group Facilitation (LGF) in an educational institution in Oman found the World Café superior in enhancing the knowledge and understanding of participants (Fullarton \& Palermo, 2008). 
Jorgenson and Steier (2013) explored World Café at the Museum of Science and Industry (MOSI) in Tampa, Florida, which has used the World Café extensively with different groups, including board and staff meetings, meetings with local community and for the planning and design of exhibitions. They analyzed two MOSI World Café events in the context of the World Café as a frame for "designed conversational processes" (Jorgenson \& Steier, 2013, p. 400).

World Café conversations focused on safety risks in a series of World Cafés involving more than 50,000 people in manufacturing plants globally. Significant progress was made with accident rates dropping by 33 percent internationally. This improvement was maintained in plants where the safety conversations continued (Hurley \& Brown, 2006). They suggest that if leaders see their organizations as a web of conversation and facilitate conversations around questions that matter, they can tap into the collective intelligence and guide action to the fulfilment of shared goals and effect change. They describe this as "conversational leadership" (Hurley \& Brown, 2006, p. 5).

Fouché and Light (2010) define the World Café as "an imaginative methodological approach" (p. 45) in their article on "Café Hear and Now" hosted in Auckland in 2006 and 2007. This was part of a bigger project that explored social work research and aimed to help develop a culture of enquiry among social workers. Participants found the World Café a useful forum for exploring their roles as practitioner researchers and identifying the workplace supports they needed in their research role. "Café Hear and Now provided a new experience in research-related activity and therefore mediated a different perception of knowledge generation" (Fouché \& Light, 2010, p. 42).

Ritch and Brennan (2010) explore a World Café used by the Centre for the Older Person's Agenda (COPA) at Queen Margaret University (QMU) in Edinburgh as a way to encourage dialogue among older people about their financial needs. Prior to the World Café, participants were asked to fill out a questionnaire regarding banking issues and equity release products. This initiated conversations on the topic and was a pre-cursor to the event itself. The model was well received and was also successful in "providing data for the research project with the bonus that participants enjoyed the event" (Ritch \& Brennan, 2010, p. 410). It was also agreed that the World Café format was a suitable environment to discuss sensitive matters such as banking and also the testing of financial products.

Burke and Sheldon (2010) report on a study of a World Café for Bassetlaw Community Health $(\mathrm{BCH})$ workers organized to create a service development/ enhancement plan. Staff appreciated being included in an opportunity to influence service developments in their area; additionally they felt their input was valued greatly. Staff gave feedback on the process itself, noting what had gone well, suggesting improvements, and articulating any concerns they had. The group devised six areas for a "service development action plan" (Burke \& Sheldon, 2010, p. 19) as an outcome of the event. 
The Well London Experience organized forty World Cafés as a means to promote "The Well London Programme," a program designed and implemented to improve the health and well-being of people living in deprived areas of London (Sheridan, Adams-Eaton, Trimble, Renton, \& Bertotti, 2010). Community engagement was a vital ingredient for the success of this scheme and that is why the World Café format was used. The cafés were called "Community Cafes." Challenges included the large numbers attending, difficulty in finding appropriate venues, engaging all sectors in the community, and selecting co-hosts. However, they found the benefits outweighed the challenges and the level of engagement ensured they delved into "deep rooted issues" (Sheridan et al., 2010, p. 48), as well as general concerns. They concluded that the participative community engagement helped to bring important improvements in community understanding of health issues as well as equipping communities with the knowledge to improve aspects of their own health and well-being.

The World Café has been used to develop business and organizational strategy and learning. In a study of a Norwegian bank and a Swedish municipal authority, Thunberg (2011) examined how dialog seminars and Café dialogs contributed to developing reflective and organizational learning. Although the dialog seminars were more formally organized than the Cafés, the goal of both was to provide a free space for reflection in a relaxed atmosphere. The bank and the municipal authority had different goals and organized their cafés in different ways, with the municipal authority focusing on communication, while the bank focused on operational matters. Although Thunberg noted that the process was very time consuming, he found everybody was more motivated by the open communication and the freedom to comment in the World Café conversations and this gave them a better sense of ownership of organizational decisions.

\section{MU world café event}

There are certain roles in a World Café and in the MU World Café, these were assigned as follows: the Café conveners were the two authors of this article whose role was to invite the people to participate. We did this through the established framework of the Academic and National Library Training Cooperative (ANLTC). The two authors also took on the role of design team whose responsibility it is to design, implement, and organize the World Café. Table hosts are members of the group who remain at tables welcoming new arrivals for each round of conversation. Our table hosts were representatives from each of the participating institutions. The members/participants were the 61 staff from the 11 participating ANLTC libraries.

This article now presents the application of the World Café model to facilitate discussion among staff from the 11 Irish University Libraries. The seven core design principles are used as a framework for the case study. 


\section{Core design principle one: It must have a context/purpose}

The MU World Café, hosted in October 2015, was part of an "Innovation Day." The theme for the day was "New Spaces and New Models for Frontline Services." This theme was selected by the ANLTC committee, which includes one of the authors of this article. It was deemed to be topical as there have has been significant changes in frontline services including the move to self-service and the provision of IT services alongside traditional library services. From the outset participants knew they would be participating in a World Café as part of the Innovation Day Programme. They approached it enthusiastically.

A variety of staffing grades were represented by the 61 participants, the majority being library assistants who have direct responsibility for service desks.

The day was structured in three parts. Following a tour of the new MU Library, a representative from each of the 11 libraries made a short presentation outlining the frontline service model in their home institution. This set the scene for the World Café that followed. It also gave a number of people their first opportunity to present to a large group of people, fulfilling broader ANLTC staff training objectives.

Prior to the World Café table hosts were identified from six of the participating institutions. It was emphasized that they were participants as well as table hosts. They were supplied with guidelines on the role of the table host by e-mail prior to the event. These guidelines were from the World Café website (www.theworldcafe. org) and explain the role of the table host, which is not that of a facilitator in the traditional sense, rather someone who welcomes new people to the table, briefly summarizes the previous discussion and ensures everyone gets an opportunity to contribute in whatever way they wish.

\section{Core design principle two: It must be in a hospitable space}

A significant part of our preparation was the physical space. A large room in our recently completed extension was used. This room is generally used by students as a "Flexible Learning Room." We set out the tables with paper tablecloths, some small vases of flowers, bowls of chocolates, and lots of pens, markers, post-its and pencils. In the World Café participants are encouraged to write/draw/doodle on the paper tablecloths. Giving people the opportunity to express themselves through drawing recognizes that people communicate differently and have different learning styles.

Posters and other materials are available to reproduce from the World Café website (World Café, 2015). While these posters convey key messages relating to the café, they are similar to artwork that might be found in a traditional café and alongside the flowers and chocolates, they add to the café ambience.

We printed posters and placed them in prominent places in the room. They were both visually engaging and a useful reminder to participants of the principles. We displayed the World Café guidelines (World Café, 2015) on a TV screen at the 
top of the room. We placed the World Café menu (World Café, 2015), alongside a printout of the World Café guidelines, on each table.

The Café followed a very sociable buffet lunch, where people had an opportunity to interact further with new colleagues. This hospitality is very much part of the World Café concept.

\section{Core design principle three: It must explore questions that matter}

The conversation in a Word Café centers on questions. The question(s) used is the key to the process, with the focus on discovery through exploring powerful questions rather than finding immediate answers. People learn together with everybody having an equal opportunity to contribute to the conversation. Questions need to be worded in a positive manner and be relatively open in order to elicit real discussion. Two to three questions are generally the maximum used. Vogt (2005, p. 165) provides the following requirements for a café question:

It is simple and clear; it is thought provoking; it generates energy; it focuses inquiry; it surfaces assumptions; it opens new possibilities (Brown \& Isaacs, 2005, p. 165)

We spent some time deliberating on questions, as we knew this was fundamental to the success of the Café and that the Café question(s) should be shaped in such a way that everyone could contribute.

We selected two questions for discussion:

- Frontline services present challenges and opportunities.

- What are they?

- What do we need to ensure a consistently high quality frontline service?

\section{Core design principe four: Everybody's contribution matters}

During a World Café participants move from table to table, contributing to a number of conversations (generally no less than three) around the same question, with different people. Through evolving rounds of dialogue, ideas merge and are reshaped, connections and patterns are established, and new perspectives emerge. People learn together with everybody having an equal opportunity to contribute to the conversation.

It is suggested that a group of 12 or more is needed for a World Café and a minimum time of 90 minutes (Brown \& Issacs, 2005). In the MU World Café, there were 61 participants across six tables with $9 / 10$ people at each at any given time, including the hosts. While we had hoped that participants would participate in three sets of conversations, each 20 minutes long, due to delays in buses getting to MU, the event ran behind schedule, and we had to limit to two rounds of conversations. Before we began the discussion, we set the context, explaining both the context and the methodology.

Once underway there was very lively dialogue with everyone participating in different ways, talking, writing, drawing, and listening. The Café host shared key 
insights from the first conversation with the second group and encouraged people to participate and to write or draw new ideas/connections throughout the conversation.

\section{Core design principle five: It connects diverse viewpoints}

At the outset, we emphasized it was important that people were not at a table with a significant number of work colleagues. We recognized that having representatives from 11 institutions offered opportunities to hear about different approaches to frontline services. The interactive nature of the café allowed library staff from the different libraries to make connections that are likely to last into the future. Networks are often regarded as a means of overcoming resource constraints (BensonRea \& Wilson, 2003). Some of the discussion in the World Café related to possible short-term job swops between institutions, similar to the Library Ireland Week Job Swop Initiative (Gardiner, 2013).

\section{Core design principle six: People listen together for insights and discoveries}

As café hosts we encouraged reflective listening and nonjudgmental consideration of everyone's contribution. Some cafés use music or interludes of poetry to create a reflective tone (Carlmark, 2005). Time constraints and the fact that we were using a room without soundproofing meant this was not an option. In the future we would like to explore methods for deeper levels of listening in this context.

\section{Core design principle seven: Participants share collective discoveries}

The final 20 minutes was an open session, which is termed “Town Hall” feedback. This was an open discussion on the feedback on both Café questions. Because of time constraints, the two authors subsequently summarized feedback and made available the key discussion points-as well as challenges and opportunities - to all participants via e-mail two weeks after the World Café. A member of staff from Maynooth University, who also participated in the World Café, took photos throughout the event: people, tablecloths, and post-its. This was subsequently made into a collage for dissemination among all participants. These photos were collated into a video slideshow and circulated to all participants.

\section{Methodology}

The World Café was the third part in a one-day program. At the end of the event, participants were given an evaluation form that related to all aspects of the day: the tour of the new library, the short presentations on frontline services in each Library, and the World Café. This is a standard ANLTC form for evaluating all ANLTC courses (see Appendix A). The standard evaluation form has four open questions:

- Which part of the day did you find most useful?

- Which part of the day did you find least useful? 
- Have you any suggestions for improvements to the course?

- What other activities would you like ANLTC to offer?

We added two further questions which related specifically to the World Café:

Is this the first time you have participated in a World Café event? If no, give details.

Would you consider taking part in a World Café in the future?

We also gathered a wide range of data from the "Town Hall" feedback, tablecloth notes, post-it notes, and photographs.

At the outset, people were told that one member of MU library staff, a member of the frontline service team, would take photographs of the event, including the tablecloths and the participants engaged in dialogue and these would be circulated to all participants and the ANLTC committee. The photographs were compiled into a video collage using the Fotor (www.fotor.com) free online software. The staff member used music composed by his daughter, a professional musician, as a backdrop to the vibrant stream of images. This recording and a collage of images of individual speakers was circulated to all participants and the ANLTC committee. As well as a useful memento of a very interesting and enjoyable day, we hoped the images would give ANLTC representatives a flavor of the World Café methodology and encourage them to consider it as a method for engagement in their libraries.

The compilation of the data was time consuming but worthwhile and writing on the tablecloths and post-its underpinned the key emerging issues documented later in this article. Much of the writing was in the form of individual words and short comments (e.g., religious awareness, footfall, eye contact with client, mentors, identify stress in students, clarify training needs, and upskill accordingly).

We listed all the individual words and sentences initially, and then grouped them into related areas. Because we were co-chairing the Café, and had moved around the room, where individual words were given, we generally understood the context (e.g., mentors) was a suggestion that more experienced staff might mentor newer staff, in a more formal manner than is now the case in most libraries. We then distilled the emerging areas into eight key areas, later reducing this to five. The feedback from the tablecloths and post-its was possibly the most useful data in terms of concerns around frontline services, as the feedback from the evaluation form related more to the organization and administration of the event and the participants' experience of the World Café as a process. While this was very useful and reinforced the value of the methodology, it did not feed into potential action around frontline service provision.

There was not a significant amount of doodling/drawing on the tablecloths, a process which has notable benefits (Kelly, 2013). Perhaps time constraints curtailed the diversity of ways participants communicated. One image depicted a building being held up by frontline staff, which clearly illustrated the artist's perception of frontline services underpinning the total library service.

The post-its and tablecloths represented feedback from the group (61) as a whole, while the evaluation form was restricted to those who opted to complete it (30). 
Again, bus schedules that delayed the start of the event made it rather rushed at the end and this is likely to be the reason for the noncompletion of the evaluation forms.

The "town hall" feedback, a 20 minute open discussion after the rounds of dialogue, related both to the process and to the concerns articulated on the tablecloths and post-its. Notes were taken and this fed into the feedback.

\section{Results and discussion}

There were 61 delegates and 30 evaluation forms were returned, which was a response rate of slightly less than $50 \%$.

In reviewing the full program, 13 respondents found the World Café the most useful part of the day. Eleven selected the presentations on frontline services in the participating libraries and the remaining six selected the tours, meeting colleagues from different institutions, and gaining insights into how other libraries operate. One person responded that it was all useful:

The group discussion and the informality of the World Café which made it easier for everyone to chat/discuss. (comment by participant)

Four respondents found the World Café too short, one found it too rushed. Participants would have liked time for more questions and discussion throughout the day.

Improvements suggested lengthening time for the World Café, having World Cafés more frequently, having smaller tables, encouraging more integration of people from different libraries, a more focused topic, and better time management throughout the day.

Participants reported that they would like more events such as the Innovation Day, more courses for frontline staff, and more opportunities to meet.

For 25 of the 30 respondents, it was their first experience of World Café. The five with previous experience of the model included staff from MU Library who participated in a World Café relating to the development of a new organizational structure in 2012 and a Library Strategic Plan 2015 World Café, and staff from Queen's University Belfast (QUB) who participated in "Civic Conversations Belfast" \& "Translating Values Workshop," both of which had used the World Café methodology. All 30 respondents said they would participate in a World Café in the future.

The Town Hall Feedback session involved the 61 attendees. Some of the feedback related to the process itself.

Very enjoyable and informative day, great to meet colleagues from other institutions and get discussions going.

The informality of the café atmosphere made it easier to speak and everyone's voice was heard.

Excellent process. We could we do it with our users.

Would have liked a longer session. 
The hospitality element was also welcomed "Chocolate is good!"

The feedback from the tablecloths, post-its, notes, and photographs was presented as a short report, with an accompanying video showing the café in action, and sent to the participants and the ANLTC committee.

The five key emerging themes are now discussed in turn.

\section{Emerging themes}

\section{Challenge of providing frontline services to an increasingly diverse user population}

Higher education institutions in the Republic of Ireland (RoI) have traditionally had a homogenous user group, comprised primarily of school leavers in the 18-21 age cohort. This is changing. Between 2005 and 2014, the number of international students enrolling in Higher Education courses has grown almost 52\% (Ireland, Higher Education Authority, 2015). In 2013/2014, the Irish Higher Education Authority (HEA) reported that $7 \%$ of all full-time undergraduate new entrants to higher education were international students: 23\% from the EU, 39\% from Asia, 26\% from North America, and 12\% from other parts of the world (Ireland, Higher Education Authority, 2015).

\footnotetext{
Ireland is targeting a doubling of the number of international student numbers attending Irish higher education institutions by 2020. (Ireland, Higher Education Authority, 2015, p. 31)
}

The feedback from the World Café indicated there is a need for customer care in the context of new user groups, including students from different ethnic backgrounds. Although percentages are still small by international standards, this group, which includes members of the Irish travelling community (0.1\%), African (0.8\%), Chinese (0.8\%), and other Asian backgrounds (1.5\%) (Ireland, Higher Education Authority, 2015), will grow and there is a need for customer care training in the context of different cultures and traditions.

In $2013 / 2014,6.6 \%$ of new entrants to higher education indicated that they have a disability, with $49.6 \%$ of this group indicating they required support for their disability. A total of $24.5 \%$ of respondents who registered as having a disability have a "psychological/emotional condition" including mental health issues (Ireland, Higher Education Authority, 2015, p. 27). This need has been recognized by the HEA who have developed the self-directed online Leadership, Equality and Diversity (LEAD) training program, which is being promoted in all HEA institutions.

In $2013 / 2014,13 \%$ of full-time undergraduate new entrants were mature ( 23 years of age or over on entry), whereas $80 \%$ of part-time undergraduate new entrants were mature (Ireland, Higher Education Authority, 2015). Participants in the World Café felt that mature students generally need more assistance from library staff. 


\section{Need to provide more with less}

Following a period of economic stringency, brought about by a severe decline in the Irish economy, staffing levels are lower than a decade ago and promotion opportunities are limited. The number of non academic staff across the Irish Higher Educational sector has dropped 14\% between 2009 and 2013 (Ireland, Higher Education Authority, 2015, p. 41).

Recurrent funding for Higher Education, across all RoI HE Institutions, fell by 32.6\% between 2009 and 2014 (Irish Universities Association, 2015). A recruitment embargo, in place until recently, curtailed the recruitment of new staff and the replacement of staff who retired and the impact of that embargo is still being felt. Articulating this helped people realize that their experience was shared by their colleagues "We are all in the same boat" and people articulated the need for acknowledgement and recognition in the workplace.

\section{Challenge of providing a consistently high level of service and changing user expectations}

Library users expect a consistently high level of service with library-related queries and increasingly non-library specific queries (e.g., IT support and specialized research support). Participants noted that frontline staff are often approached with queries that relate to other areas on campus and issues that are not library specific. They felt that the Library is often perceived as a "one-stop-shop." While frontline staff are often very capable at answering a variety of queries, it can increase workloads and requires broader knowledge.

Another change for most of the participating libraries is that they now work alongside colleagues from the Institution's IT department. This model-an IT help desk with or near the information desk-is relatively new in Irish University libraries. Library users expect a high level of customer service be it from library staff or IT staff, they do not distinguish between the services, although they may have different priorities and service ethos.

\section{Marketing the library and promoting service}

Some of the feedback from participants in the World Café related to library marketing and promotion, with a recognition that frontline service is key to the marketing of the Library. The question arose as to whether we are doing enough to promote what we do. It was noted that effective marketing can be done on a relatively small budget with a diverse range of social media and many of the participating libraries have an effective social media presence. Participants noted that frontline staff also have a responsibility to promote services such as information about subject librarians, information skills tutorials and referencing classes run by librarians. 


\section{Need for constant upskilling and professional development and the lack of opportunities for career advancement}

Library users' needs are constantly changing and evolving. Library staff must keep up to date with new developments such as discovery solutions and self-service developments. The Academic and National Library Training Co-operative (ANLTC), was established in 1995 as a collaborative partnership to provide training opportunities for the library sector and runs a program of short courses each year. The Library Association of Ireland (LAI) also provide a range of programs, including the 23 Things online program, which covers using social media and webbased tools. The LIR HEAnet User Group for Libraries runs an annual seminar on technological advancements that many library staff attend.

The "job swop" initiative, which is part of Library Ireland Week, offers one-day job swop opportunities, which can be enriching as noted by Gardiner, who found it offered an "opportunity to see how the library service operates in a different environment" (Gardiner, 2013, p. 24).

At a local level, most ANLTC-member institutions have institutional staff development offices. These internal units traditionally offer courses that are not library specific (e.g., presentation skills, using MS Office, etc.). However, these units have also suffered from budgetary constraints. Individual university units such as Student Services and Access Office provide a range of in-house events. These are frequently briefings on dealing with mental health issues, student stress and various disabilities including Asperger's Syndrome. Libraries also provide on the job training and briefings on topics such as discovery solutions, in-house IT systems, VLE's and using specific information resources. A more formal system of mentoring was suggested as a possible way to address the need for constant upskilling.

Because of the nature of frontline service provision and the need for back up staff, providing developmental opportunities for frontline staff can present challenges.

As in most countries, for a library assistant to progress to a librarian post they must complete a Master of Library and Information Studies. While there are now distance education opportunities, completing such programs requires time and money. While some institutions provide funding toward these programs, this is not the case across the sector.

Another challenge is staff mobility. With a population of 4.6 million people (Central Statistics Office, 2015) and seven Universities, the RoI is small and there is a limited number of libraries and library posts.

There was a recognition and discussion of these issues during the Café.

\section{Conclusion}

While the dialogue in the World Café is extremely valuable as a process, it is important that it leads to action. We submitted a short report to participants and 
to ANLTC. In our report we suggested action at both local and national level (via ANLTC) over an 18-month period.

At the local level we recommended that frontline staff should be encouraged and facilitated to participate in the self-directed online LEAD (Living, Equality, and Diversity) program (https://www.leadequalitynetwork.com/). We also recommended that locally, libraries work with university units such as Student Services/Access Office, among others, to arrange training for frontline/library staff on how to offer the best customer service for a diverse user body. At the national level (ANLTC), we suggested organizing a seminar devoted to frontline service provision in 2016, which would bring back together many of the participants in the World Café.

We found the World Café was a creative way of generating discussion and sharing experiences of frontline service provision. It gave participants an opportunity to share their views, discuss their concerns, and make suggestions. The World Café had a context and a clear purpose and this was vital to ensuring its success. The fact that issues of concern to all were explored provided a sense of cohesion to the process. Participants got to talk about issues that concerned them with colleagues from other libraries and got a good sense of what is happening nationally. The Café moved away from traditional seminar methods where participants are frequently the recipients of knowledge created elsewhere to being engaged in the process of knowledge creation through sharing experiences and information. The method generated a sense of inclusiveness; all were equal participants in the conversation regardless of their institution or post.

This was the first Library World Café offered to staff from all Irish university libraries. It provided a new experience for many of the participants and a different perception of how feedback could by elicited and knowledge generated and shared. Some of the participants remarked that they would use World Café in their own organizations. Having library staff from Queens University Belfast (QUB) was also very insightful for participants. The two universities in Northern Ireland; University of Ulster (UU) and QUB are part of the UK higher education system and had different experiences to share, including the QUB recent Customer Service Excellence Award (Traynor, 2015)

Hosting a World Café is definitely more time consuming than hosting a traditional seminar or meeting. However, we feel it was worthwhile. The fact that the café was shorter than we had planned is a limitation, but we would hope that further practice and research will build on this experience. Overall, this was a very positive experience and something we would certainly consider doing again in the future.

\section{References}

Benson-Rea, M., \& Wilson, H. (2003). Networks, learning and the lifecycle. European Management Journal, 21(5), 588-597. doi:10.1016/S0263-2373(03)00108-7

Brown, J., \& Isaacs, D. (2005). The world café: Shaping our futures through conversations that matter. San Francisco, CA: Berrett-Koehler. 
Brown, J., Isaacs, D., Margulies, N., \& Warhaftig, G. (1999). The World Café: Catalyzing largescale collective learning. Leverage Magazine, 33, 1-2.

Brown, J., Issacs, D., \& Tan, S. (2008). Multi-generational collaboration: Shaping tomorrow, together. Kosmos, 7(2), 32-33.

Burke, C., \& Sheldon, K. (2010). Encouraging workplace innovation using "World Cafe" model. Nursing Management, 17(7), 14-19.

Carlmark, C. (2005). What's in the middle of the table? Scandinavian sustainability forum. In J. Brown \& D. Isaacs (Eds.). The world café: Shaping our futures through conversations that matter (pp. 124-136). San Francisco, CA: Berrett-Koehler.

Fallon, H., \& Bean, E. (2014). Hosting a world café: Experiences at the National University of Ireland Maynooth. SCONUL Focus, 60, 72-74.

Fouché, C., \& Light, G. (2010). An invitation to dialogue: "The World Café" in Social Work. Qualitative Social Work, 10(1), 28-48. doi:10.1177/1473325010376016

Fullarton, C., \& Palermo, J. (2008). Evaluation of a large group method in an educational Institution: The World café versus Large Group facilitation. Journal of Institutional Research, 14(1), 109-117.

Gardiner, B. (2013). Library Ireland Week Staff Exchange Scheme: Diary of an exchange. An Leabharlann. The Irish Library, 22(1), 23-24.

Ireland, Central Statistics Office. (2015). Population and migration estimates April 2015. Retrieved from http://www.cso.ie/en/releasesandpublications/er/pme/populationandmigra tionestimatesapril2015/

Ireland, Higher Education Authority. (2015). Key facts and figures: Higher Education 2013/14. Retrieved from http://www.hea.ie/sites/default/files/final_key_facts_figures_2013_14.pdf

Ireland, Oireachtas Library and Research Service. (2014). Higher education in Ireland: For economy and society? (p. 2). Retrieved from http://www.oireachtas.ie/parliament/media/housesof theoireachtas/libraryresearch/spotlights/Spotlight_higher_education_for_upload_155719.pdf

Hovath, B. (2005). Building on traditions of dialogue: Saudi Aramco. In J. Brown \& D. Isaacs (Eds.), The world café: Shaping our futures through conversations that matter (pp. 71-77). San Francisco, CA: Berrett-Koehler.

Hurley, T., \& Brown, J. (2009). Conversational leadership: Thinking together for a change. The Systems Thinker, 20(9), 2-7.

Irish Universities Association. (2015). University fast facts. Retrieved http://www.iua.ie/theirish-universities/university-fast-facts/

Jorgenson, J., \& Steier, F. (2013). Frames, framing, and designed conversational processes Lessons from the World Café. The Journal of Applied Behavioural Science, 49(3), 388-405. doi:10.1177/0021886313484511

Kelly, S. (2013). The benefits of using graphic recording/graphic facilitation. Retrieved from http://www.theworldcafe.com/wp-content/uploads/2015/07/graphicBenefits.pdf

Ritch, E. L., \& Brennan, C. (2010). Using World Café and drama to explore older people's experience of financial products and services. International Journal of Consumer Studies, 34(4), 405-411. doi:10.1111/j.1470-6431.2010.00881.x

Schieffer, A., Isaacs, D., \& Gyllenpalm, B. (2004). The World Café: Part one. World, 18 (8), 1-9.

Senge, P. M. (1990). The fifth discipline: The art and practice of the learning organization. New York, NY: Currency Doubleday.

Sheridan, K., Adams-Eaton, F., Trimble, A., Renton, A., \& Bertotti, M. (2010). Community engagement using World Café: The Well London Experience. Groupwork, 20(3), 32-50.

Thunberg, O. A. (2011). World cafés and dialog seminars as processes for reflective learning in organisations. Reflective Practice, 12(3), 319-333. doi:10.1080/14623943.2011.571864

Traynor, E. (2015). Customer Service Excellence (CSE) in Library Services, Queen's University Belfast. SCONUL Focus, 64, 5-7. 
Vogt, E. (2005). The World Cafe Hosting Guide. In J. Brown \& D. Isaacs, (Eds.), The world café: Shaping our futures through conversations that matter (pp. 162-175). San Francisco, CA: Berrett-Koehler.

World Café. (2015). Guidelines. Retrieved from http://www.theworldcafe.org

World Café Community Foundation. (2015). A quick reference guide for hosting World Café. Retrieved from http://www.theworldcafe.com/wp-content/uploads/2015/07/Cafe-To-GoRevised.pdf

\section{Appendix A}

\section{Evaluation Form}

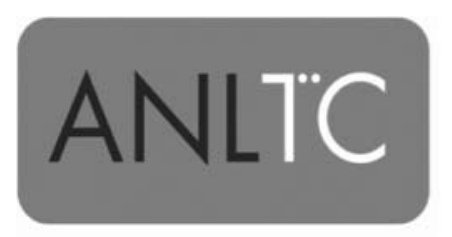

Academic and National Library

Training Co-operative

anitc.conul.ie

CONUL (Staff Training and Development)

Course Title:

Presenter:

Venue:

Date:

We would be grateful if you would complete the following evaluation form. This will help us in planning future programmes.

Please rate each statement below by ticking the appropriate box.

\begin{tabular}{|c|c|c|c|c|}
\hline & StronglyDisagree & Disagree & Agree & StronglyAgree \\
\hline \multicolumn{5}{|l|}{ Content and Design } \\
\hline The objectives for the course were clearly identified & 0 & 0 & 0 & 0 \\
\hline The course was relevant to my needs & 0 & 0 & 0 & 0 \\
\hline The pace of the course was appropriate & 0 & 0 & 0 & 0 \\
\hline Handouts/materials were appropriate and useful & 0 & 0 & 0 & 0 \\
\hline Practical sessions were well organized & 0 & 0 & 0 & 0 \\
\hline Subject matter was covered to an appropriate level & 0 & 0 & 0 & 0 \\
\hline \multicolumn{5}{|l|}{ Presentation } \\
\hline Presenter demonstrated good knowledge of subject & 0 & 0 & 0 & 0 \\
\hline The material was presented clearly & 0 & 0 & 0 & 0 \\
\hline The pace of the presenter was appropriate & 0 & 0 & 0 & 0 \\
\hline The presenter was responsive to questions & 0 & 0 & 0 & 0 \\
\hline Audio-visual aids were high quality and effective & o & 0 & 0 & o \\
\hline \multicolumn{5}{|l|}{ Venue and Administration } \\
\hline Pre course administration was satisfactory & 0 & 0 & 0 & 0 \\
\hline The training room was comfortable & 0 & 0 & 0 & 0 \\
\hline Equipment for sessions was satisfactory & 0 & 0 & 0 & 0 \\
\hline The catering was good & 0 & 0 & 0 & 0 \\
\hline \multicolumn{5}{|l|}{ Overall Course Satisfaction } \\
\hline Overall the course met my objectives & 0 & 0 & 0 & 0 \\
\hline Overall I was satisfied with this course & 0 & 0 & 0 & 0 \\
\hline
\end{tabular}




\section{Open Questions}

1.Which part of the course did you find most useful?

2.Which part of the course did you find least useful?

Have you any other suggestions for improvements to the course?

4. What other activities would you like to ANLTC to offer?

5.Any other comments or suggestions?

Thank you for taking the time to complete this questionnaire 